\title{
A new modified Gant-Miwa-Thiersch combined with submucosal and perirectal sclerosant injection procedure for full-thickness rectal prolapse in elderly women: clinical analysis of 34 cases
}

Jinxi Wang ${ }^{1+}$, Huiyu $\mathrm{Li}^{1+}$, Xiaoming $\mathrm{Ma}^{2}$, Gang Du${ }^{1}$, Jun Ma ${ }^{1}$, Xiaojing Ren ${ }^{1}$, Fang Zhang ${ }^{1}$, Xiushan Dong ${ }^{1}$, Haoliang Zhao ${ }^{1}$ and Chongren Ren ${ }^{1,3^{*}}$

\begin{abstract}
Background: Full-thickness rectal prolapse (FTRP) frequently occurs in elderly women, and more than 100 surgical procedures have been proposed to restore FTRP. The Gant-Miwa-Thiersch (GMT) procedure is the most used treatment in China. However, the recurrence rate of FTRP post-GMT, which is as high as $23.8 \%$, is concerning. We described a new modified GMT combined with internal and external rectal sclerosant injection (nmGMTSI) procedure to address this problem.

Methods: The nmGMTSI was performed under spinal anesthesia in 34 frail, elderly female patients with FTRP. The surgical results of FTRP were assessed. Fecal incontinence and constipation were evaluated using the Wexner score, and anal canal rest pressure (ACRP), maximum anal systolic pressure (MASP), anorectal sensation thresholds (AST), and maximum rectal tolerance (MRT) using anorectal manometry preoperatively and postoperatively. The causes of recurrence and complications were analyzed.

Results: All patients were cured according to the clinical cure standard. The perioperative Wexner fecal incontinence score (WFIS) was $10.3 \pm 3.31$, which became $3.7 \pm 2.43(P<0.0001)$ postoperatively. The perioperative ACRP was $2.0 \pm 0.56 \mathrm{kPa}$, which became $8.5 \pm 2.25 \mathrm{kPa}(\mathrm{P}<0.0001)$ postoperatively. The perioperative MASP was $4.5 \pm 1.16 \mathrm{kPa}$, which became $18.6 \pm 2.50 \mathrm{kPa}(\mathrm{P}<0.0001)$ postoperatively. However, no significant difference was observed between the preoperative and postoperative Wexner constipation scores (WCS) $(17.3 \pm 2.25 \mathrm{vs} .15 .4 \pm 2.89, P=0.1047)$. The perioperative and postoperative AST were $38.1 \pm 5.34 \mathrm{~mL}$ and $23.5 \pm 3.61 \mathrm{~mL}$, respectively $(P=0.0002)$. The maximum rectal tolerance (MRT) was $157.1 \pm 16.73 \mathrm{~mL}$, which became $121.2 \pm 12.45 \mathrm{~mL}$ postoperatively $(P=0.0009)$. The patients developed no serious postoperative complications. The total relapse rate after nmGMTSI was $2.9 \%$ in the median two years follow-up period. The most common cause of relapse after nmGMTSI was the removal of infected threads used in the Thiersch procedure.
\end{abstract}

\footnotetext{
*Correspondence: renxiangxiang@126.com

†Jinxi Wang and Huiyu Li have contributed equally to this article

1 Shanxi Bethune Hospital, Taiyuan 030012, People's Republic of China

Full list of author information is available at the end of the article
}

(c) The Author(s) 2021. Open Access This article is licensed under a Creative Commons Attribution 4.0 International License, which permits use, sharing, adaptation, distribution and reproduction in any medium or format, as long as you give appropriate credit to the original author(s) and the source, provide a link to the Creative Commons licence, and indicate if changes were made. The images or other third party material in this article are included in the article's Creative Commons licence, unless indicated otherwise in a credit line to the material. If material is not included in the article's Creative Commons licence and your intended use is not permitted by statutory regulation or exceeds the permitted use, you will need to obtain permission directly from the copyright holder. To view a copy of this licence, visit http://creativecommons.org/licenses/by/4.0/. The Creative Commons Public Domain Dedication waiver (http://creativeco mmons.org/publicdomain/zero/1.0/) applies to the data made available in this article, unless otherwise stated in a credit line to the data. 
Conclusion: The benefits of nmGMTSI include low rates of recurrence, complications, and mortality, cost-effectiveness, wide adaptation, minimal invasiveness, and technical simplicity. Hence, it should be considered the first option for the treatment of FTRP in frail elderly women.

Keywords: Rectal prolapse, Full-thickness rectal prolapse, Gant-Miwa-Thiersch procedure, nmGMTSI, Recurrence

\section{Background}

Full-thickness rectal prolapse (FTRP) frequently occurs in older women [1]. Its chief clinical feature is a mass protruding from the anus following defecation. Occasionally, the symptoms of FTRP may occur spontaneously while coughing or weight-bearing. FTRP is a debilitating condition with a complex etiology, with obstetric trauma as the most common, iatrogenic sphincter injury during hemorrhoidectomy and fistula surgery, and external injury to the perineum [2].

More than 100 surgical procedures have been proposed to restore FTRP. The operative procedures for rectal prolapse can be broadly categorized as either abdominal or perineal approaches [3]. Traditionally, the perineal approach has been chosen for older, high-risk patients because of fewer surgical complications, shorter surgery time, and simpler anesthesia. Perineal procedures can be classified into the two following categories: procedures to initiate fibrosis, such as submucosal sclerosant injection, and procedures to shorten the prolapsed rectum, such as Delorme's operation, Altemeier's operation, stapled transanal rectal resection (STARR), and GantMiwa-Thiersch (GMT). The GMT procedure is the most common treatment in China and Japan [4, 5]. However, the recurrence rate of FTRP after GMT is as high as $23.8 \%$ [4].

We described a new modified GMT combined with internal and external rectal sclerosant injection (nmGMTSI) procedure to address this problem. To the best of our knowledge, this is the first reported case of such an approach to treat FTRP, with significant results in frail elderly women.

\section{Methods}

\section{Patient selection}

From January 2016 to December 2018, female patients diagnosed with FTRP based on clinical examination [6] who underwent nmGMTSI at the Colorectal Surgery Unit of Shanxi Bethune Hospital were recruited. Patients were recruited based on the following criteria: age $>65$ years; length of rectal prolapse $>4 \mathrm{~cm}$; unfit for general anesthesia with chronic heart failure, chronic obstructive pulmonary disease, chronic renal failure requiring hemodialysis, liver cirrhosis, and other conditions. In contrast, patients with FTRP were excluded based on the following criteria: enterocele or cystocele by bimanual examination; malignant colorectal tumors; life expectancy $<2$ years; severe colonic transit dysfunction by colon transfer test; recurrent rectal prolapse; absolute contraindication of surgery by whole blood cell analysis, blood clotting index, hepatic and renal function, and routine fecal tests.

All operations were performed by the same surgical team members of the unit. To guarantee the quality of surgery, the main surgeon of the study had 10 years of working experience at the Colorectal Surgery Unit of Shanxi Bethune Hospital. The surgical results of FTRP were assessed by clinical symptoms and bowel function. The bowel function of all patients in the study was measured for fecal incontinence and constipation using the Wexner score, anal canal rest pressure (ACRP), maximum anal systolic pressure (MASP), anorectal sensation thresholds (AST), and maximum rectal tolerance (MRT) by anorectal manometry before and 24 months after surgery. Patients were followed up every $3,6,12$, and 24 months in the outpatient clinic.

\section{Operative procedures}

Surgery was performed under spinal anesthesia, and cephalosporin was administered $0.5 \mathrm{~h}$ before the operation. The patient was placed in lithotomy and Trendelenburg positions to prevent the small intestine from slipping into the Douglas pouch. The prolapsed rectum was pulled out of the anus completely using Babcock forceps, and the anus was inspected using a rotating speculum anoscope. First, the rectal mucosa was transfixed by a $2 / 0$ Vicryl thread at the $3,6,9$, and 12 o'clock positions, $5 \mathrm{~cm}$ above the surface of the prolapsed mucosa. The threads were not cut and pulled in four directions (Fig. 1a). Second, while grasping the prolapsed mucosa using hemostatic forceps, the grips on the prolapsed rectal mucosa were ligated using a $3 / 0$ silk thread to create a tag; this procedure was repeated in multiple transverse and longitudinal lines that were arranged at $0.5 \mathrm{~cm}$ intervals without excising the tag (Fig. 1b). Third, the sclerosant $(1 \mathrm{~mL}, 50 \%$ XiaoZhiLing) was injected into the rectal submucosa proximal to the mucosal plication (Fig. 1c). Fourthly, the prolapsed rectal mucosa $1 \mathrm{~cm}$ above the dentate line was sutured with a previously uncut Vicryl thread 2/0 (Fig. 1d). Fifth, the prolapsed rectum was completely restored by tightening the Vicryl thread (Fig. 1e). Sixth, the index 

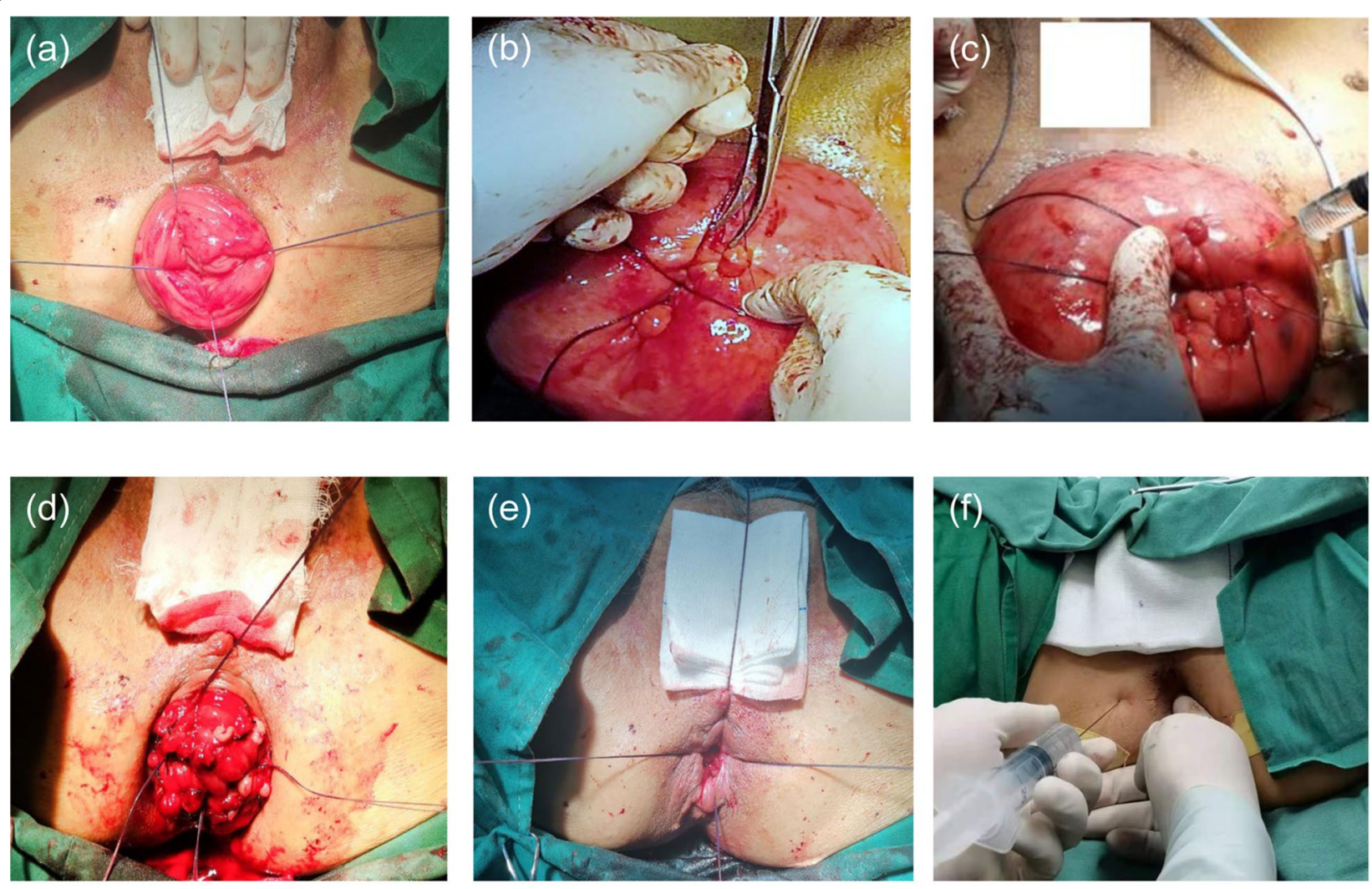

(g)
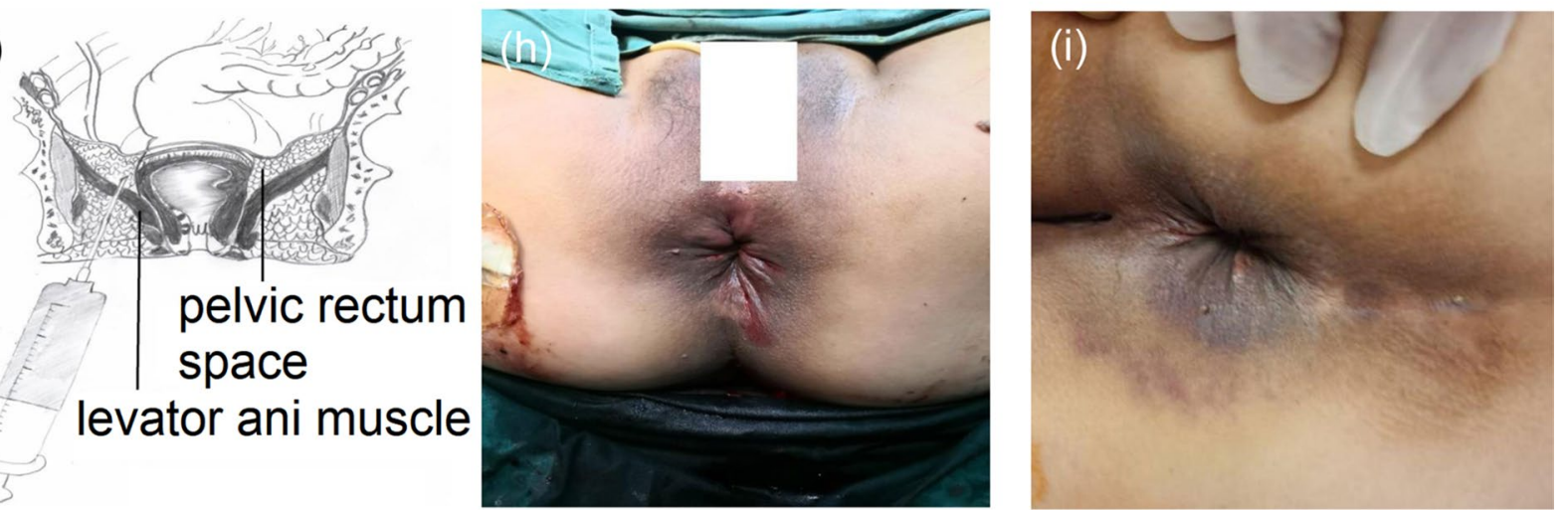

Fig. 1 Operative procedure for a new modified Gant-Miwa-Thiersch (GMT) combined with internal and external rectal sclerosant injection (nmGMTSI). a The prolapsed rectum was pulled out of the anus completely. Grips of the rectal mucosa were transfixed by a 2/0 Vicryl thread at the 3, 6, 9, and 12 o'clock positions, $5 \mathrm{~cm}$ above the surface of the prolapsed mucosa. $\mathbf{b}$ Grips of rectal prolapsed mucosa were transfixed by silk thread. c Sclerosant was injected into the rectal submucosa proximal to mucosal plication. $\mathbf{d}$ The prolapsed rectal mucosa $1 \mathrm{~cm}$ above the dentate line was sutured with the previous uncut Vicryl thread 2/0. e The prolapsed rectum was restored completely by tightening the Vicryl thread. f Sclerosant was injected into the pelvic rectum space. $\mathbf{g}$ Anatomic drawings of the injection in the pelvic rectum space. $\mathbf{h}$ The Thiersch procedure was performed. $\mathbf{i}$ The results on clinical follow-up three months after surgery

finger was placed into the rectum, and the needle was inserted $8 \mathrm{~cm}$ from the $1.5 \mathrm{~cm}$ anal verge in the 3 and 9 o'clock positions. Under the guidance of the index finger and ultrasound, the sclerosant $(20 \mathrm{~mL} 100 \%$ XiaoZhiLing) was injected into the pelvic rectum space
(Fig. 1f, g). Finally, four 3-mm-long vertical incisions were made in the midline of the anal verge anteriorly and posteriorly at the $3,6,9$ and 12 o'clock positions. All the incisions were sutured using a 0 Vicryl thread to encircle the entire anal verge, and the suture was tied over an index finger (Fig. 1h). 


\section{Statistical analyses}

SPSS 22.0 statistical software was used for data analysis. The measurement data were analyzed by Student's $t$-test and expressed as the mean + standard deviation. A value of $\mathrm{P}<0.05$ was considered statistically significant.

\section{Results}

Between January 2016 and December 2018, a total of 34 female patients with FTRP underwent nmGMTSI. The clinical characteristics of the patients are listed in Table 1. The median age was $76.2 \pm 9.14$ years (range $65-87$ years), while the BMI was $17.3 \pm 4.5 \mathrm{~kg} / \mathrm{m}^{2}$ (range 12-23) with most patients underweight. All patients complained of a mass protruding through the anus. In $85.3 \%$ of patients, the mass protruded occasionally; in $14.7 \%$ of patients, the mass protruded at all times. The initial condition in most patients was diarrhea or fecal incontinence $(76.4 \%)$, while constipation was the initial presentation in $23.6 \%$ of patients. Some patients presented with abdominal or anal pain, blood discharge, and mucus discharge (Table 1). To explore the etiology of FTRP, the risk factors for FTRP are provided in Table 2. The potential risk factors analyzed were multiparity, chronic obstructive pulmonary disease, malnutrition, redundant rectosigmoid colon, previous pelvic surgery, colitis, and irritable bowel syndrome. This result was slightly different from that in Western societies.

To analyze the causes of recurrence and complications, hospital stay, operative time and intraoperative and postoperative complications were examined (Table 3). The average hospitalization time was $7.3 \pm 1.6$ days (range 5-9), and most of the patients were discharged before one week. The median operative time was $44 \pm 12 \mathrm{~min}$ (range 30-60 min). The symptoms of FTRP disappeared

Table 1 Clinical characteristics of patients undergoing nmGMTSI for full-thickness rectal prolapse

\begin{tabular}{ll}
\hline & $\begin{array}{l}\text { Total } \\
\text { population } \\
(\mathbf{n}=\mathbf{3 4 )}\end{array}$ \\
\hline Age mean $\pm \mathrm{SD}$ (years) & $76.2 \pm 9.14$ \\
$\mathrm{BMI}\left(\mathrm{kg} / \mathrm{m}^{2}\right)$ mean $\pm \mathrm{SD}$ & $19.3 \pm 4.5$ \\
Symptoms & \\
Feeling of a bulge in the rectum during defecation & $29(85.3 \%)$ \\
Feelings of prolapse without defecating & $1(14.7 \%)$ \\
Diarrhea/Fecal incontinence & $26(76.4 \%)$ \\
Constipation/obstructed defecation & $8(23.5 \%)$ \\
Abdominal or anal pain & $8(24 \%)$ \\
Blood discharge & $13(38.2 \%)$ \\
Mucus discharge & $10(29.4 \%)$ \\
\hline
\end{tabular}

$S D$ standard deviation, $B M I$ body mass index
Table 2 Risk factors for full-thickness rectal prolapse

\begin{tabular}{lc}
\hline Factors & $\begin{array}{l}\text { Total } \\
\text { population } \\
\text { (n=34) }\end{array}$ \\
\hline Vaginal delivery $\geq 3$ & $29(85.3 \%)$ \\
$<3$ & $5(14.7 \%)$ \\
Chronic obstructive pulmonary disease & $23(67.6 \%)$ \\
Malnutrition/long-term vegetarians & $21(61.7 \%)$ \\
Redundant rectosigmoid colon & $18(52.9 \%)$ \\
Previous pelvic surgery & $13(38.2 \%)$ \\
IBD or colitis & $12(35.3 \%)$ \\
IBS & $8(23.5 \%)$ \\
Solitary rectal ulcer & $5(14.7 \%)$ \\
Family history of rectal prolapse & $4(11.8 \%)$ \\
\hline
\end{tabular}

IBD inflammatory bowel disease, IBS inflammatory bowel syndrome

completely after surgery in all patients. All patients were cured according to clinical cure standard (Fig. 1i) [6]. Twenty-six patients suffered from preoperative diarrhea or fecal incontinence, which improved in 25 patients after surgery. The perioperative Wexner fecal incontinence score (WFIS) was $10.3 \pm 3.31$, which became $3.7 \pm 2.43$ $(\mathrm{P}<0.0001)$ postoperatively. The perioperative and postoperative ACRP were $2.0 \pm 0.56 \mathrm{kPa}$ and $8.5 \pm 2.25 \mathrm{kPa}$, respectively $(\mathrm{P}<0.0001)$. The MASP was $4.5 \pm 1.16 \mathrm{kPa}$, which became $18.6 \pm 2.50 \mathrm{kPa}$ postoperatively $(\mathrm{P}<0.0001)$ (Fig. 2a). Eight patients experienced preoperative constipation, which improved in four patients after surgery. However, no significant difference was observed between preoperative and postoperative Wexner constipation scores (WCS) (17.3 \pm 2.25 vs. $15.4 \pm 2.89$, $\mathrm{P}=0.1047)$. The perioperative and postoperative AST were $38.1 \pm 5.34 \mathrm{~mL}$ and $23.5 \pm 3.61 \mathrm{~mL}$, respectively $(P=0.0002)$. The perioperative and postoperative MRT

Table 3 Surgical management, results, and complications

\begin{tabular}{ll}
\hline & Numbers \\
\hline Hospital stays (days) & $7.3 \pm 1.6$ \\
Operative time (min) & $44 \pm 12$ \\
FTRP curative ratio & $34 / 34(100 \%)$ \\
Curative ratio of diarrhea or fecal incontinence & $25 / 26(96.2 \%)$ \\
Curative ratio of constipation & $4 / 8(50.0 \%)$ \\
Recurrence of rectal prolapse & $1 / 34(2.9 \%)$ \\
Rectal bleeding & 3 \\
Ischemic colitis & 2 \\
Urinary retention & 2 \\
Stenosis of the rectum & 1 \\
Perianal abscess & 1 \\
Infection of the thread used for the Thiersch procedure & 1
\end{tabular}

FTRP full thickness rectal prolapse 


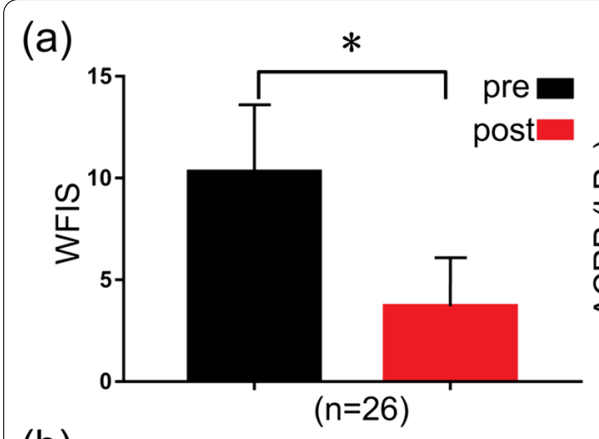

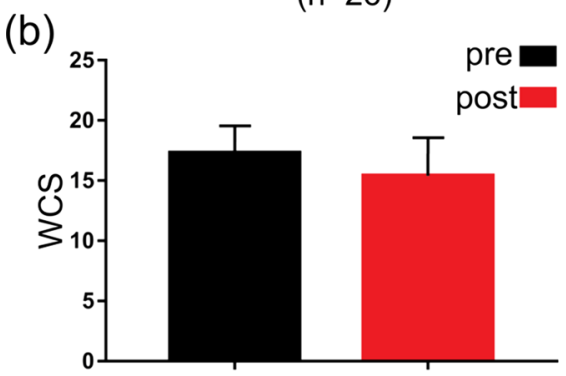

$(n=8)$

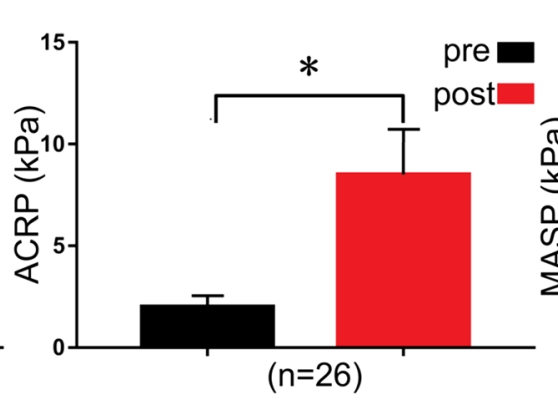

*

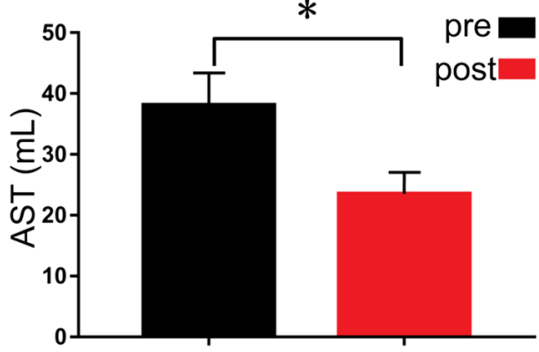

$(n=8)$

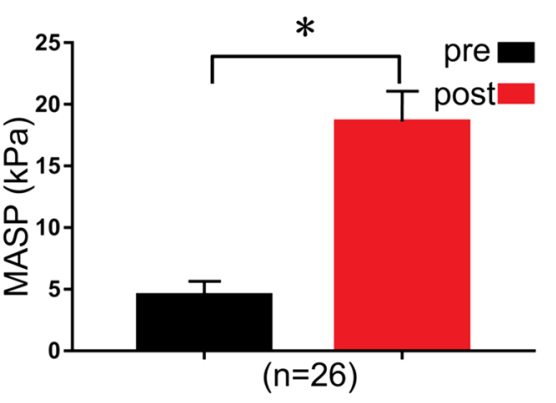

*

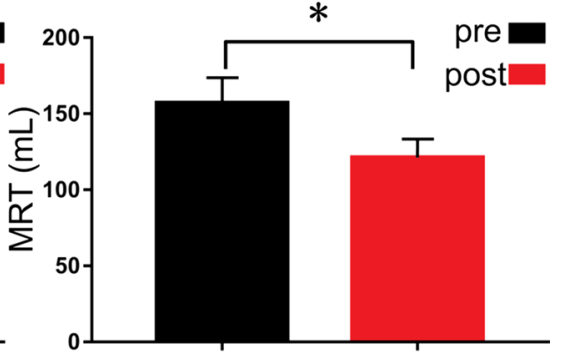

$(n=8)$

Fig. 2 Surgical results of nmGMTSI. a Improvement in incontinence after nmGMTSI. WFIS, ACRP, and MASP were evaluated for patients preoperatively and postoperatively. Quantitative data (mean \pm SD) were shown; ${ }^{*} P<0.05$, Student's $t$-test. pre: preoperative, post: postoperative. b Partial improvement in constipation incontinence after nmGMTSI. WCS, AST, and MRT were evaluated for patients preoperatively and postoperatively. Wexner fecal incontinence score: WFIS; anal canal rest pressure: ACRP; maximum anal systolic pressure: MASP; Wexner constipation scores: WCS; anorectal sensation thresholds: AST; maximum rectal tolerance: MRT

were $157.1 \pm 16.73 \mathrm{~mL}$ and $121.2 \pm 12.45 \mathrm{~mL}$, respectively $(\mathrm{P}=0.0009)$. (Fig. 2b). Three patients $(8.8 \%)$ developed rectal bleeding, which was controlled using an anal pack and conservative measures. Two patients (5.9\%) showed urinary retention after surgery, which was controlled by indwelling catheters for 1 week. Two patients (5.9\%) showed ischemic colitis, which was controlled by conservative measures. One patient (2.9\%) developed rectal stenosis 6 months after the operation, and this was controlled by dilatation of the anus with a metal anoscope. Lastly, one patient $(2.9 \%)$ showed a perianal abscess at 12 months after the operation, which was due to the infection of the thread used for the Thiersch procedure. Anti-infective therapy was ineffective, and rectal prolapse recurred one year after the infected thread had been removed.

\section{Discussion}

There are two types of rectal prolapse as follows: Type I, which is also called mucosal prolapse, involves the protrusion of the mucosa and is usually less than $3 \mathrm{~cm}$ long; Type II, also called FTRP, involves full-thickness extrusion of the rectal wall characterized by concentric folds in the prolapsed mucosa [6]. FTRP commonly affects older women, and this study focused on the treatment of FTRP in older women, in whom the length of rectal prolapse is $>4 \mathrm{~cm}$.

The various approaches of FTRP can be classified into two as follows: transabdominal and transperineal [3]. The choice of the initial treatment was based on the assessment, age, comorbidities, and grading of prolapse. Transperineal surgery consists of Delorme's, Altemeier's, STARR, and GMT operations. Delorme's procedure involves mucosal and submucosal dissection, plication of the remaining muscle layer, and mucosal anastomosis. Delorme's procedure has been reported to cause significant bleeding and perforation after surgery [7]. Altemeier's procedure involves excision of the redundant rectum or sigmoid colon, and it is more appropriate for obstructive defecation syndrome [8]. It has a risk of fatal complications, such as anastomotic breakdown, rectal bleeding, and perianal abscess. This approach has been reported to have a postoperative mortality rate of $1.6 \%$ after surgery $[9,10]$. The STARR operation involves excision of the redundant rectal mucosa with a colorectal anastomosis that only applies to a mucosal protrusion of less than $5 \mathrm{~cm}$ long $[11,12]$. Since FTRP is a benign disease, the operative method should be simple with wide adaptation and low postoperative mortality rate and cost.

One surgical technique for FTRP is the GMT (mucosal plication with anal encircling), which can be used 
irrespective of the length of the rectum and colon prolapse [4]. Iida et al. reported no postoperative complications in 166 patients who underwent GMT. GMT is not popular in the western world, while it plays a major role in the treatment of FTRP in China and Japan [4, 5]. Possible reasons include anatomical and dietary factors. In Western societies, an elongated sigmoid colon is commonly observed in elderly institutionalized patients with chronic constipation. A redundant, elongated sigmoid colon is prone to rectal prolapse [13]. In China, the pathophysiology of FTRP is usually related to several anatomic concerns, such as obstetric trauma, causing weakness of pelvic floor muscles associated with connective tissue MMP-1(Matrix Metalloproteinases), a proteolytic enzyme involved in chronic obstructive pulmonary disease. This leads to loosely attached rectal mucosa (to the underlying muscularis) [14] (Table 2) and osteoporosis-induced malnutrition and aging, resulting in loss of the normal sacral curvature and the curvature of the rectum $[15,16]$. Constipation seldom occurs partly due to the long-term vegetarian lifestyle in China [17]. Diarrhea or fecal incontinence was thought to be the common accompanying symptoms of FTRP (Table1). Clinical results of GMT showed improved defecation with minimal complications [18]. Therefore, in selecting surgical approaches, the exact causative factors and anatomical variations should be considered and tailored according to the patient's disease characteristics. However, the recurrence rate after GMT was $23.8 \%$ within a maximum follow-up period of 14 years [4]. We modified the GMT and combined it with square transfixion with submucosal and ischiorectal space injection sclerotherapy to address this problem.

Compared to GMT, we made the following three improvements in nmGMTSI: First, the grip of the full thickness of the rectal wall was transfixed by a $2 / 0$ Vicryl thread at the 3, 6, 9, and 12 o'clock positions, $5 \mathrm{~cm}$ above the surface of the prolapsed mucosa. Similar to GMT, multiple tags were created. After the rectal mucosa, the tissue $1 \mathrm{~cm}$ above the dentate line was sutured with the previously uncut Vicryl thread 2/0, and the prolapsed rectum was completely restored by tightening the Vicryl thread. This improvement can significantly shorten the operation time and prevent recurrence in the short term after surgery, in which inflammatory adhesions have not yet formed. Second, longitudinal injection of the sclerosant in each of the four quadrants of the rectal submucosal area promotes inflammatory response and scarring, which prevents long-term mucosal prolapse recurrence. Finally, the sclerosant was injected into the pelvic rectal space. This improvement was mainly due to the weakness of the pelvic floor muscles associated with connective tissue. The sclerosant initiates an inflammatory reaction resulting in fibrosis outside the rectal wall, and the perirectal tissue that leads to the wall of the rectum adheres to the perirectal tissue, preventing recurrence of prolapse of the rectal wall. Of course, sclerosant should be avoided in the anal sphincter.

Evaluation of the nmGMTSI depends on the results and complications of the surgery. As shown in Table 3, some of our patients had comorbidity; however, they all recovered satisfactorily from surgery. No perforation of the rectum or colon was observed. This may reflect the fact that nmGMTSI is a safe and extremely effective operating method. In this study, the WFIS was significantly lower after surgery (Fig. 2a). Our study findings are consistent with those of the study of Yamana et al. [18], as we observed improvement in incontinence in more than $96.2 \%$ of patients (Table 3). One possible explanation is that the ACRP and MASP were significantly increased after anal encircling, and the wall of the rectum adhered to the perirectal tissue (Fig. 2a). Constipation partially improved in this study (Table 3). The AST and MRT were downregulated postoperatively compared to the preoperative values. However, no significant difference was between the preoperative and postoperative WCS (Fig. 2b). One possible reason is that scar formation in the rectal submucosal area would result in outlet obstruction. As shown in Table 3, some patients developed complications, such as bleeding, colitis, and stenosis; however, they all recovered satisfactorily with conservative therapies. Notably, the thread used for anal encircling can be infected, and its removal was usually necessary. In such cases, recurrence tends to occur after removal.

In our study, the overall recurrence rate after nmGMTSI was $2.9 \%$ during a period of two years with no operative death. The nmGMTSI is effective for diarrhea or fecal incontinence. There are, of course, some limitations to this research. The postoperative follow-up time was not long enough, and the patients' satisfaction scores were not validated. The nmGMTSI is less effective for cases of constipation or obstructed defecation.

\section{Conclusion}

The nmGMTSI has various benefits, including wide adaptation, minimal invasiveness, technical simplicity, cost-effectiveness, and low rates of complications, mortality, and recurrence. Hence, we recommend this procedure be used as the first choice for FTRP in frail elderly women with pelvic floor muscle weakness.

\section{Abbreviations}

FTRP: Full-thickness rectal prolapse; STARR: Stapled transanal rectal resection; GMT: Gant-Miwa-Thiersch; nmGMTSI: New modified GMT combined with internal and external rectal sclerosant injection; WFIS: Wexner fecal incontinence score; ACRP: Anal canal rest pressure; MASP: Maximum anal systolic pressure; WCS: Wexner constipation scores; AST: Anorectal sensation 
thresholds; MRT: Maximum rectal tolerance; IBD: Inflammatory bowel disease; IBS: Irritable bowel syndrome.

\section{Acknowledgements}

Not applicable.

\section{Authors' contributions}

JW and HL wrote the manuscript. XM, GD, and JM performed all operations. $X R$ and $F Z$ did all the analysis and drew figures. XD, HZ and CR designed the study and revised the manuscript. All authors read and approved the final manuscript.

\section{Funding}

This study was funded by the "136 medical developing Project" of Shanxi Province, P. R. China.

\section{Availability of data and materials}

All data generated or analyzed during this study are available from the corresponding author on reasonable request.

\section{Declarations}

\section{Ethics approval and consent to participate}

The study was authorized by the ethics committee of Shanxi Medical University (Approval Number: YXLL-2016-008). The study methodology conformed to the standards set by the Declaration of Helsinki. Each patient was informed of the contingent risks of the study and provided written informed consent.

\section{Consent for publication}

All authors approved the final manuscript for publication. Written informed consent was obtained from the patients and/or their legal guardians for publication, and any accompanying images, sex, age of these patients.

\section{Competing interests}

The authors declare that they have no competing interests.

\section{Author details}

${ }^{1}$ Shanxi Bethune Hospital, Taiyuan 030012, People's Republic of China. ${ }^{2}$ Burn Treatment Center of Shanxi Province, Tisco General Hospital, Taiyuan 030000 , People's Republic of China. ${ }^{3}$ Department of Colorectal Surgery, Shanxi Bethune Hospital, Longcheng Street 99, Taiyuan 030012, People's Republic of China.

Received: 13 April 2021 Accepted: 31 May 2021

Published online: 05 June 2021

\section{References}

1. Gourgiotis S, Baratsis S. Rectal prolapse. Int J Colorectal Dis. 2007;22:231-43.

2. Kumar N, Kumar D. Fecal incontinence and rectal prolapse. Indian J Gastroenterol. 2019:38:465-9.

3. Hrabe J, Gurland B. Optimizing treatment for rectal prolapse. Clin Colon Rectal Surg. 2016:29:271-6.
4. lida Y, Honda K Saitou H, Munemoto Y, Tanaka H. Modified Gant-MiwaThiersch procedure (mucosal plication with anal encircling) for rectal prolapse. Colorectal Dis. 2019;21:588-94.

5. Shen Z, Yang GG, Zhang XF, Qiu JM, Yu YY. Clinical analysis of 31 cases with rectal prolapse undergoing modified Gant-Miwa procedure and anal encircling. Zhonghua Wei Chang Wai Ke Za Zhi. 2013;16:641-4.

6. van der Schans EM, Paulides TJC, Wijffels NA, Consten ECJ. Management of patients with rectal prolapse: the 2017 Dutch guidelines. Tech Coloproctol. 2018:22:589-96.

7. Marchal F, Bresler L, Ayav A, Zarnegar R, Brunaud L, Duchamp C, et al. Long-term results of Delorme's procedure and Orr-Loygue rectopexy to treat complete rectal prolapse. Dis Colon Rectum. 2005;48:1785-90.

8. Trompetto M, Tutino R, Realis Luc A, Novelli E, Gallo G, Clerico G. Altemeier's procedure for complete rectal prolapse; outcome and function in 43 consecutive female patients. BMC Surg. 2019;19:1.

9. Pinheiro LV, Leal RF, Coy CS, Fagundes JJ, Martinez CA, Ayrizono ML. Longterm outcome of perineal rectosigmoidectomy for rectal prolapse. Int J Surg. 2016;32:78-82.

10. Kim M, Reibetanz J, Schlegel N, Krajinovic K, Köstler H, Germer CT, et al. Recurrence after perineal rectosigmoidectomy: when and why? Colorectal Dis. 2014;16:920-4

11. Picciariello A, Papagni V, Martines G, De Fazio M, Digennaro R, Altomare DF. Post-operative clinical, manometric, and defecographic findings in patients undergoing unsuccessful STARR operation for obstructed defecation. Int J Colorectal Dis. 2019:34:837-42.

12. Zanella S, Spirch S, Scarpa M, Ricci F, Lumachi F. Long-term outcome of stapled transanal rectal resection (STARR) versus stapled hemorrhoidopexys (STH) for grade III-IV hemorrhoids: preliminary results. In Vivo. 2014;28:1171-4.

13. Sun C, Hull T, Ozuner G. Risk factors and clinical characteristics of rectal prolapse in young patients. J Visc Surg. 2014:151:425-9.

14. Cao LL, Yu J, Yang ZL, Qiao X, Ye H, Xi CL, et al. MMP-1/TIMP-1 expressions in rectal submucosa of females with obstructed defecation syndrome associated with internal rectal prolapse. Histol Histopathol. 2019;34:265-74.

15. du Kim H, Sung DH, Min YK. Hypophosphatemic osteomalacia induced by low-dose adefovir therapy: focus on manifestations in the skeletal system and literature review. J Bone Miner Metab. 2013:31:240-6.

16. Zhu Z, Xu L, Zhu F, Jiang L, Wang Z, Liu Z, et al. Sagittal alignment of spine and pelvis in asymptomatic adults: norms in Chinese populations. Spine (Phila Pa 1976). 2014;39(1):E1-6.

17. Liu Y, Gao X, Ding Y, Zhou Y, Liu X, Wang H, et al. Effectiveness and safety of light vegetarian diet on functional constipation with gastrointestinal damp-heat pattern: an exploratory study protocol for randomized controlled trial. Medicine (Baltimore). 2019;98:e18325.

18. Yamana T, Iwadare J. Mucosal plication (Gant-Miwa procedure) with anal encircling for rectal prolapse-a review of the Japanese experience. Dis Colon Rectum. 2003;46(10 Suppl):S94-9.

\section{Publisher's Note}

Springer Nature remains neutral with regard to jurisdictional claims in published maps and institutional affiliations.

Ready to submit your research? Choose BMC and benefit from:

- fast, convenient online submission

- thorough peer review by experienced researchers in your field

- rapid publication on acceptance

- support for research data, including large and complex data types

- gold Open Access which fosters wider collaboration and increased citations

- maximum visibility for your research: over $100 \mathrm{M}$ website views per year

At $\mathrm{BMC}$, research is always in progress.

Learn more biomedcentral.com/submissions 